\title{
Statistics of Single-Degree-of-Freedom Estimate of Displacement for Pushover Analysis of Buildings
}

\author{
Anil K. Chopra, Rakesh K. Goel, and Chatpan Chintanapakdee
}

\begin{abstract}
Investigated is the basic premise that the roof displacement of a multistory building can be determined from the deformation of a single-degree-of-freedom (SDF) system. The responses of both systems are determined rigorously by nonlinear response history analysis, without introducing any of the approximations underlying the simplified methods for estimating the deformation of a SDF system (see, e.g., FEMA-273 or ATC-40 guidelines). The statistics of the SDF system estimate of roof displacement are presented for a variety of generic frames and six SAC buildings subjected to ground motion ensembles. Data obtained for generic frames indicate that the first "mode" SDF system overestimates the median roof displacement for systems subjected to large ductility demand $\mu$, but underestimates for small $\mu$. The bias and dispersion tend to increase for longer period system for every value of $\mu$. Similar data for SAC buildings demonstrate that the bias and dispersion on the SDF estimate of roof displacement increases when P-delta effects (due to gravity loads) are included. The modal pushover analysis procedure has the advantage of reducing the dispersion in the roof displacement and the underestimation of the median roof displacement for elastic or nearly elastic cases at the expense of increasing slightly the overestimate of roof displacement of buildings responding far into the inelastic range.
\end{abstract}

\section{Introduction}

Current structural engineering practice estimates seismic demands by the nonlinear static procedure or pushover analysis detailed in Federal Emergency Management Agency FEMA-273 (Building Seismic Safety Council 1997) or Applied Technology Council (ATC-40) guidelines (ATC 1996). The seismic demands are computed by nonlinear static analysis of the structure subjected to monotonically increasing lateral forces with an invariant heightwise distribution until a target value of roof displacement is reached. This roof displacement value is determined from the earthquake-induced deformation of an inelastic single-degree-offreedom (SDF) system derived from the pushover curve. This estimate of roof displacement has been compared with the "exact" value from nonlinear response history analysis (RHA) (Miranda 1991; Collins et al. 1996; Miranda 1997; Miranda 1999; Gupta and Krawinkler 2000).

This work investigates the basic premise that the roof displacement of a multistory building can be determined from the deformation of the first-mode SDF system. For this purpose, the responses of both systems are determined rigorously by nonlinear

\footnotetext{
${ }^{1}$ Johnson Professor, Dept. of Civil and Environmental Engineering, Univ. of California, Berkeley, CA 94720-1710.

${ }^{2}$ Associate Professor, Dept. of Civil and Environmental Engineering, California Polytechnic State Univ., San Luis Obispo, CA 93407.

${ }^{3}$ Graduate Student, Dept. of Civil and Environmental Engineering, Univ. of California, Berkeley, CA 94720-1710.
}

RHA, without introducing any of the approximations underlying the simplified methods for estimating the deformation of a SDF system (see, e.g., FEMA-273 or ATC-40 guidelines). The statistics of the SDF system estimate of roof displacement are presented for a variety of frame buildings and ground motion ensembles, and improved results are achieved by modal pushover analysis (Chopra and Goel 2002).

\section{Structural Systems, Ground Motions, and Response Statistics}

\section{Structural Systems and Ground Motions}

Two sets of structural systems and ground motions are considered. The first set is generic one-bay frames of six different heights: $3,6,9,12,15$, and 18 stories. The height-wise distribution of stiffness is defined to achieve equal drifts in all stories under the lateral forces specified in the International Building Code (IBC). Assuming that the second moment of cross-sectional area for each beam and its supporting columns in the story below are the same, numerical values for the flexural rigidities of structural elements were selected such that the fundamental vibration period is defined $T_{1}=0.045 H^{0.8}$, the mean $+1 \mathrm{SD}$ of measured periods (Goel and Chopra 1997). Frames with $T_{1}=0.028 H^{0.8}$, the mean -1 SD of data, were also analyzed (Chintanapakdee and Chopra 2003), but their results are not included here for brevity. The frames are designed according to the strong-column-weakbeam philosophy, therefore, plastic hinges form only at beam ends and the base of the first-story columns. Bending moment yield strength distribution is designed such that yielding occurs simultaneously at all plastic hinges under the IBC lateral force distribution. The yield base shear is selected as $V_{b y}=\left(A_{y} / g\right) W$, where $W$ is the total weight of the frame and $A_{y}$ is the median (over 20 ground motions) pseudoacceleration for a SDF system 
with vibration period $T_{n}=T_{1}$ and ductility factor $\mu=1,1.5,2,4$, and 6; five different designs are considered for each frame height.

The seismic excitation for these generic frames is defined by a set of 20 large-magnitude-small-distance records listed in Chintanapakdee and Chopra (2003). These ground motions were obtained from California earthquakes with magnitudes ranging from 6.6 to 6.9 recorded at distances of $13-30 \mathrm{~km}$.

The second set of structural systems will be referred to as SAC buildings. SAC commissioned three consulting firms to design 3-, 9-, and 20-story model buildings with symmetric plan according to the local code requirements of three cities: Los Angeles, Seattle, and Boston. Described in detail in Gupta and Krawinkler (1999), the structural systems of these model buildings consisted of perimeter steel moment-resisting frames. The North-South perimeter frames of 9- and 20-story buildings are the second set of systems analyzed in this paper for two conditions: excluding or including P-delta effects due to gravity loads.

For all three locations, sets of 20 ground motion records were assembled representing probabilities of exceedance of 2 and $10 \%$ in 50 years (return periods of 2,475 and 475 years, respectively) (Somerville et al. 1997). The 2/50 set of records is used in the subsequent analysis.

\section{Response Statistics}

The dynamic response of each structural system to each of the 20 ground motions was determined by the three procedures described in the next section: nonlinear RHA, uncoupled modal response history analysis (UMRHA), and modal pushover analysis (MPA). Including only the first "mode" contribution in the latter two approximate procedures provides the SDF system estimate of response. The "exact" peak value of roof displacement $u_{r}$ determined by nonlinear RHA is denoted by $\left(u_{r}\right)_{\mathrm{NL}-\mathrm{RHA}}$, the approximate value from MPA by $\left(u_{r}\right)_{\mathrm{MPA}}$, and the SDF system estimate by $\left(u_{r}\right)_{\mathrm{SDF}}$. From these data for each ground motion, two displacement ratios are determined: $\left(u_{r}^{*}\right)_{\mathrm{SDF}}=\left(u_{r}\right)_{\mathrm{SDF}} \div\left(u_{r}\right)_{\mathrm{NL}-\mathrm{RHA}}$ and $\left(u_{r}^{*}\right)_{\mathrm{MPA}}=\left(u_{r}\right)_{\mathrm{MPA}} \div\left(u_{r}\right)_{\mathrm{NL}-\mathrm{RHA}}$. An approximate method is invariably biased in the sense that the median of the displacement ratio differs from one, underestimates the median response if the ratio is less than one, and provides an overestimate if the ratio exceeds one.

Presented in this paper are $n(=20)$ observed values, $x_{i}$ of a displacement ratio in the form of a histogram, the median value $\hat{x}$ defined as the geometric mean and the dispersion measure $\delta$ defined as

$$
\begin{aligned}
& \hat{x}=\exp \left[\frac{\sum_{i=1}^{n} \ln x_{i}}{n}\right] \\
& \delta=\left[\frac{\sum_{i=1}^{n}\left(\ln x_{i}-\ln \hat{x}\right)^{2}}{n-1}\right]^{1 / 2}
\end{aligned}
$$

For small values, e.g., 0.3 or less, the above dispersion measure is close to the coefficient of variation. In subsequent sections we will loosely use the term "dispersion" when referring to this measure. Eqs. 1(a) and 1(b) are logical estimators for the median and dispersion, especially if the data are sampled from lognormal distribution (Benjamin and Cornell 1970), which is known to be appropriate for earthquake response of structures. In the case where one or more excitations caused collapse of the building or its first-"mode" SDF system, the median and dispersion were estimated by a counting method. The 20 data values for a displacement ratio were sorted in ascending order, the median was estimated as the average of the 10th and 11th values starting from the lowest value; the 84 th percentile value as the 17 th value; and the dispersion $=\log (84$ th percentile value $)-\log$ (median value).

Before presenting such response data for inelastic response of the selected systems, their response assuming elastic behavior will be considered. In this case the nonlinear RHA procedure specializes to linear RHA and the MPA procedure to standard response spectrum analysis (RSA); thus, the latter displacement ratio is written as: $\left(u_{r}^{*}\right)_{\mathrm{RSA}}=\left(u_{r}\right)_{\mathrm{RSA}} \div\left(u_{r}\right)_{\mathrm{RHA}}$.

\section{Roof Displacement: Elastic Analysis Procedures}

Developed in Chopra et al. (2001) and summarized below are three procedures to determine roof displacement.

\section{Modal Response History Analysis}

The contribution of the $n$th vibration mode to roof displacement $u_{r}(t)$ is

$$
u_{r n}(t)=\Gamma_{n} \phi_{r n} D_{n}(t)
$$

where $D_{n}(t)$ is governed by the equation of motion for the $n$th mode linear SDF system, a SDF system with vibration properties-natural frequency $\omega_{n}\left(\operatorname{period} T_{n}=2 \pi / \omega_{n}\right)$ and damping ratio $\zeta_{n}$-of the $n$th mode of the MDF system, subjected to earthquake ground motion $\ddot{u}_{g}(t)$

$$
\ddot{D}_{n}+2 \zeta_{n} \omega_{n} \dot{D}_{n}+\omega_{n}^{2} D_{n}=-\ddot{u}_{g}(t)
$$

where $\phi_{r n}=$ value at the roof in the $n$th mode $\phi_{n}$ and

$$
\Gamma_{n}=\frac{L_{n}}{M_{n}} \quad L_{n}=\boldsymbol{\phi}_{n}^{T} \mathbf{m} \mathbf{\iota} \quad M_{n}=\boldsymbol{\phi}_{n}^{T} \mathbf{m} \boldsymbol{\phi}_{n}
$$

where $\mathbf{m}=$ mass matrix and each element of the influence vector $\mathbf{t}$ is equal to unity.

The roof displacement considering the contributions of all vibration modes is

$$
u_{r}(t)=\sum_{n=1}^{N} u_{r n}(t)=\sum_{n=1}^{N} \Gamma_{n} \phi_{r n} D_{n}(t)
$$

and its peak (or maximum absolute) value over time is denoted by $\left(u_{r}\right)_{\mathrm{RHA}}$.

\section{Modal Response Spectrum Analysis}

The peak value of the roof displacement can be estimated directly from the response spectrum for the ground motion without carrying out the RHA implied in Eqs. (2)-(5). In such an RSA, the peak value $u_{r n o}$ of the $n$th mode contribution $u_{r n}(t)$ to roof displacement $u_{r}(t)$ is determined from

$$
u_{r n o}=\Gamma_{n} \phi_{r n} D_{n}
$$

where $D_{n}=$ peak value of deformation $D_{n}(t)$. Eq. (3) was solved to obtain all results represented later in this paper. For practical application, however, $D_{n}$ can be determined as the ordinate $D\left(T_{n}, \zeta_{n}\right)$ of the deformation response (or design) spectrum.

For planar analysis of symmetric-plan buildings with wellseparated frequencies, the peak modal responses are combined according to the square-root-of-sum-of-squares (SRSS) rule to obtain an estimate of the total roof displacement: 

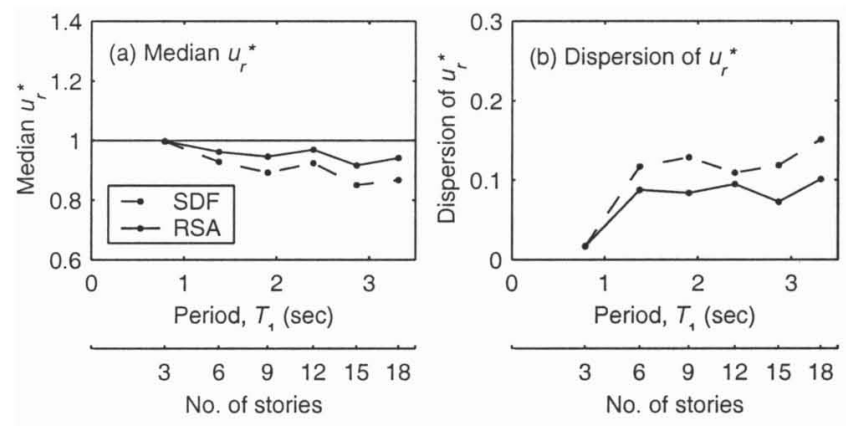

Fig. 1. Median and dispersion of $\left(u_{r}^{*}\right)_{\mathrm{SDF}}$ and $\left(u_{r}^{*}\right)_{\mathrm{RSA}}$ versus fundamental vibration period $T_{1}$ for generic elastic frames

$$
\left(u_{r}\right)_{\mathrm{RSA}}=\left(\sum_{n=1}^{N} u_{r n o}^{2}\right)^{1 / 2}
$$

\section{Single-Degree-of-Freedom System Estimate}

Considering only the first-mode response leads to a SDF system estimate of the roof displacement, which is defined by Eq. (7), specialized for the first mode

$$
\left(u_{r}\right)_{\mathrm{SDF}}=\Gamma_{1} \phi_{r 1} D_{1}
$$

\section{Comparative Evaluation of Analysis Procedures: Elastic Buildings}

\section{Generic Frames}

Fig. 1 shows the median and dispersion of the ratio $\left(u_{r}^{*}\right)_{\mathrm{SDF}}$ for elastic frames plotted against the fundamental vibration period (or number of stories). This ratio starts very close to 1.0 for the 3 -story frame and decreases to 0.85 for the 15 -story frame, indicating that the SDF estimate $\left(u_{r}\right)_{\mathrm{SDF}}$ is biased in the sense that it underestimates the roof displacement and that this bias increases for taller (or longer period) frames. The SDF system consistently underestimates the roof displacement because it ignores the higher mode contributions known to be increasingly significant as the fundamental period lengthens (Chopra 2001, Chap. 18). For the same reasons, dispersion starts at close to zero for the 3-story frame and increases to 0.15 for the 18 -story frame.

When higher-mode contributions are included in RSA, the median of the ratio $\left(u_{r}^{*}\right)_{\mathrm{RSA}}$ becomes closer to 1.0 compared to $\left(u_{r}^{*}\right)_{\mathrm{SDF}}$, indicating that the bias-although still an underestimation-has decreased [see Fig. 1(a)]. Because the peak modal response for each mode is computed exactly by RHA, the remaining bias is entirely due to approximations associated with the modal combination rule [Eq. (7)]. While this source of approximation is well known, it should be noted that the bias is consistently an underestimation. The dispersion of roof displacement is also reduced when higher mode contributions are included.

While the median and dispersion of the displacement ratio $\left(u_{r}^{*}\right)_{\mathrm{SDF}}$ are two important sample statistics, data for individual ground motions are also of interest. For this purpose, histograms of the 20 values of the ratio are plotted in Fig. 2. Note that while the SDF system provides an accurate estimate of displacement of the 3-story frame for every ground motion, it underestimates the displacement of the 6-story and taller frames for a majority of

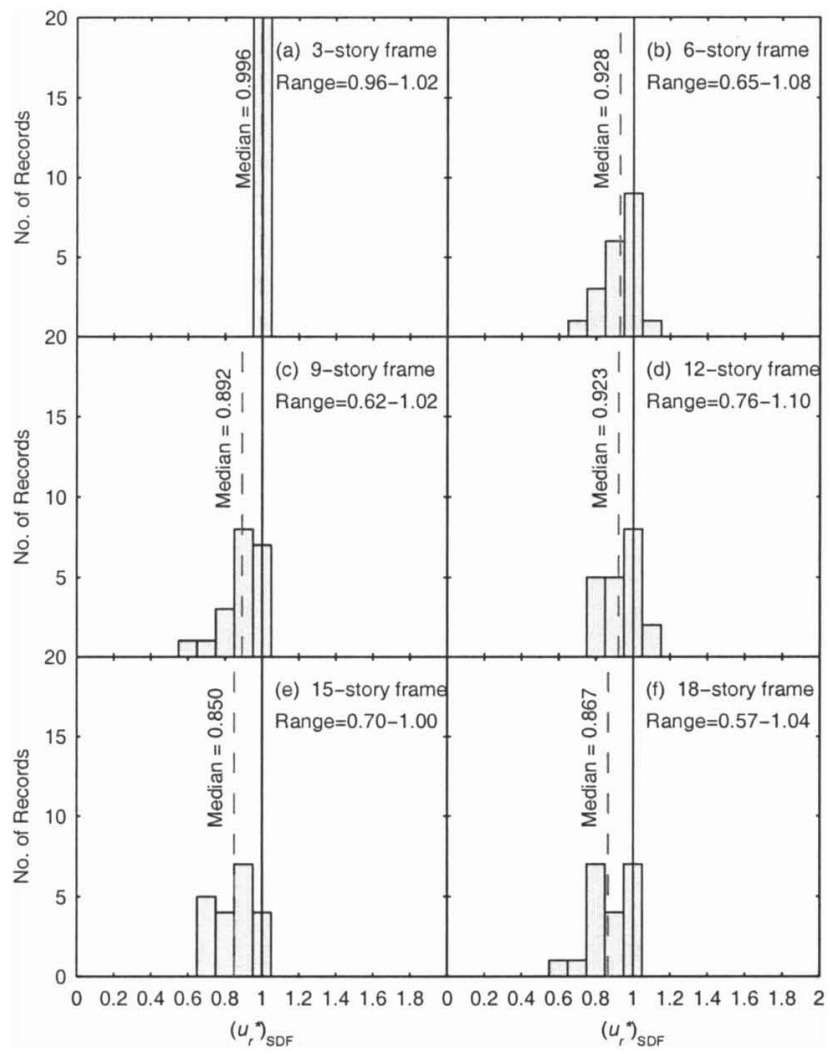

Fig. 2. Histograms of ratio $\left(u_{r}^{*}\right)_{\mathrm{SDF}}$ for generic elastic frames; range of values and median value of this ratio are noted

excitations. This estimate can be alarmingly small for a few excitations. The smallest values of $\left(u_{r}^{*}\right)_{\mathrm{SDF}}$ encountered are 0.96 , $0.65,0.62,0.76,0.70$, and 0.57 for $3-, 6-, 9-, 12-, 15-$, and $18-$ story frames, respectively. This large underestimation of roof displacement is investigated further in Chopra et al. (2001).

\section{SAC Buildings}

The earthquake response of each building to each SAC ground motion is computed under the assumption that the structure remains elastic. Table 1 shows the median and dispersion of the ratio $\left(u_{r}^{*}\right)_{\mathrm{SDF}}$ for the six SAC buildings. The median ratio is less than 1.0, indicating that the SDF system estimate $\left(u_{r}\right)_{\mathrm{SDF}}$ is biased toward underestimating the roof displacement because the higher mode contributions are ignored. The bias and dispersion vary among the three 9-story buildings (and the three 20-story buildings) because the significance of higher mode responses depends on their fundamental vibration period and on the frequency characteristics of different sets of ground motions for the three locations. For each location-with one exception-the bias and dispersion are smaller for the 9-story building because the fundamental mode contribution is more dominant in its roof displacement compared to the 20-story structure. As expected, when higher mode contributions are included in RSA, the bias and dispersion decrease; the remaining bias is associated with the modal combination rule. As in the case of generic frames, the roof displacement is consistently underestimated, even if all significant modes are included.

The histograms of the 20 values of the displacement ratio $\left(u_{r}^{*}\right)_{\mathrm{SDF}}$ for each of the six SAC buildings (Fig. 3) indicate that the SDF system underestimates the roof displacement of 9-story 
Table 1. Median and Dispersion of $\left(u_{r}^{*}\right)_{\mathrm{SDF}}$ and $\left(u_{r}^{*}\right)_{\mathrm{RSA}}$ for SAC Buildings Analyzed as Elastic Systems

$\begin{array}{lccccc} & T_{1} & & \left(u_{r}^{*}\right)_{\mathrm{SDF}} & & \text { Median } \\ \text { Building } & (\mathrm{s}) & \text { Median } & \text { Dispersion } & 0.147 & 0.949 \\ \text { Boston 9 story } & 3.11 & 0.829 & 0.184 & 0.956 \\ \text { Boston 20 story } & 3.11 & 0.783 & 0.160 & 0.912 & 0.135 \\ \text { Seattle 9 story } & 2.99 & 0.821 & 0.165 & 0.868 \\ \text { Seattle 20 story } & 3.76 & 0.741 & 0.128 & 0.942 \\ \text { Los Angeles 9 story } & 2.27 & 0.912 & 0.110 & 0.0955 \\ \text { Los Angeles 20 story } & 3.81 & 0.881 & 0.930\end{array}$

buildings due to 19,18 , and 17 of the 20 ground motions for Boston, Seattle, and Los Angeles locations, respectively; for 20story buildings it is underestimated by all excitations except one for the Boston structure. This estimate of roof displacement is surprisingly small for a few excitations. The roof displacement is underestimated by as much as 46,41 , and $40 \%$ for 9 -story buildings in Boston, Seattle, and Los Angeles, and by 47, 43, and 39\% for 20 -story buildings in these three locations.

To investigate this large underestimation of roof displacement, the response history of modal contributions and of the combined value of roof displacement for the Los Angeles 9-story building due to two of the 20 ground motions is presented in Fig. 4; also included is the $\left(u_{r}\right)_{\mathrm{RSA}}$ value determined from Eq. (7). Consistent with the prevailing view, the first mode for one of these excitations is strongly dominant; as shown in Fig. 4(a), the SDF system estimate of roof displacement is essentially exact (192 versus 191 $\mathrm{cm})$. For another excitation, however, the SDF system estimate $(48.6 \mathrm{~cm})$ is $40 \%$ less than the "exact" value $(80.8 \mathrm{~cm})$. If the

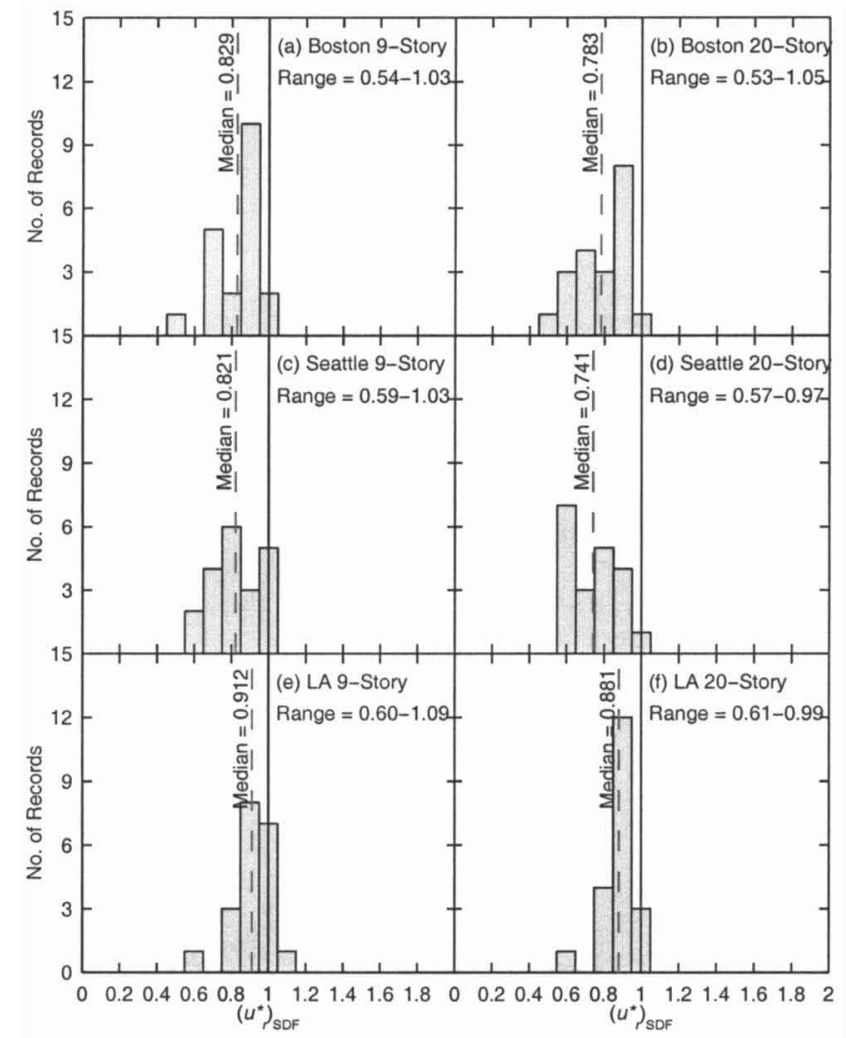

Fig. 3. Histograms of ratio $\left(u_{r}^{*}\right)_{\mathrm{SDF}}$ for SAC buildings analyzed as elastic systems; range of values and median value of this ratio are noted contributions of the first three modes are included in RSA, the underestimation is reduced to $28 \%(58.6 \mathrm{~cm}$ versus $80.8 \mathrm{~cm})$.

\section{Roof Displacement: Inelastic Analysis Procedures}

\section{Nonlinear Response History Analysis}

The rigorous approach is to solve directly the coupled equations of motion for inelastic systems, leading to the "exact" nonlinear response history analysis (NL-RHA) procedure. The peak value of roof displacement determined by this procedure is denoted as $\left(u_{r}\right)_{\mathrm{NL}-\mathrm{RHA}} \cdot$

\section{Uncoupled Modal Response History Analysis}

If the equations of motions for inelastic systems are transformed to modal coordinates $q_{n}$ of the corresponding linear system, they remain coupled. Neglecting this coupling leads to the UMRHA procedure (Chopra et al. 2001; Chopra and Goel 2002). This approximate RHA procedure facilitates investigating the SDF system estimate of roof displacement of inelastic multi-degree-offreedom (MDF) systems.

The spatial distribution $\mathbf{s}=\mathbf{m} \mathbf{l}$ of the effective earthquake forces $\mathbf{p}_{\text {eff }}(t)=-\mathbf{m} \mathbf{u} \ddot{u}_{g}(t)$ is expanded into the modal contributions $\mathbf{s}_{n}$ according to

$$
\mathbf{m} \mathbf{}=\sum_{n=1}^{N} \mathbf{s}_{n}=\sum_{n=1}^{N} \Gamma_{n} \mathbf{m} \boldsymbol{\phi}_{n}
$$

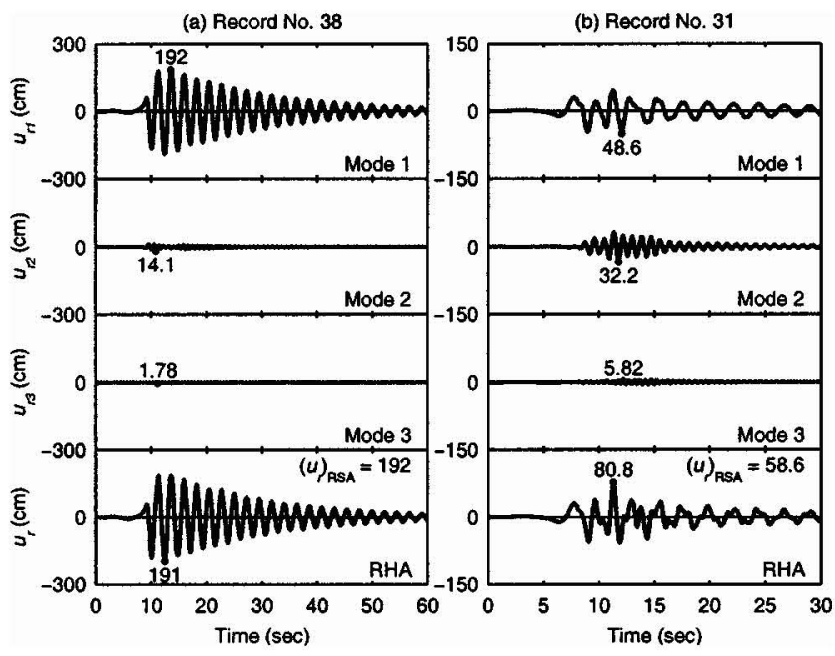

Fig. 4. Modal contributions to roof displacement of Los Angeles nine-story building analyzed as elastic system to SAC ground motions: (a) record No. 38; (b) record No. 31; response spectrum analysis estimate of roof displacement is also noted 
where $\boldsymbol{\phi}_{n}=$ modes of the corresponding linear system. The effective earthquake forces can then be expressed as

$$
\mathbf{p}_{\text {eff }}(t)=\sum_{n=1}^{N} \mathbf{p}_{\text {eff }, n}(t)=\sum_{n=1}^{N}-\mathbf{s}_{n} \ddot{u}_{g}(t)
$$

The contribution of the $n$th mode to $\mathbf{s}$ and to $\mathbf{p}_{\mathrm{eff}}(t)$ are

$$
\begin{gathered}
\mathbf{s}_{n}=\Gamma_{n} \mathbf{m} \phi_{n} \\
\mathbf{p}_{\mathrm{eff}, n}(t)=-\mathbf{s}_{n} \ddot{u}_{g}(t)
\end{gathered}
$$

In the UMRHA procedure, the response of the inelastic multistory building to $\mathbf{p}_{\mathrm{eff}, n}(t)$ given by Eq. $(11 b)$, is determined approximately from Eq. (2) where $D_{n}(t)$ is now governed by

$$
\ddot{D}_{n}+2 \zeta_{n} \omega_{n} \dot{D}_{n}+\frac{F_{s n}\left(D_{n}, \operatorname{sign} \dot{D}_{n}\right)}{L_{n}}=-\ddot{u}_{g}(t)
$$

Eq. (12) may be interpreted as the governing equation for the $n$th "mode" inelastic SDF system, a SDF system with: (1) small amplitude vibration properties - natural frequency $\omega_{n}$ and damping ratio $\zeta_{n}$-of the $n$th mode of the corresponding linear MDF system; and (2) $F_{s n} / L_{n}-D_{n}$ relation between resisting force $F_{s n} / L_{n}$ and modal coordinate $D_{n}$. As described in Chopra and Goel (2002), this force deformation relation is derived from the pushover curve, a plot of base shear $V_{b n}$ against roof displacement $u_{r n}$ determined by nonlinear static analysis of the structure subjected to lateral forces distributed over the building height according to

$$
\mathbf{s}_{n}^{*}=\mathbf{m}_{n}
$$

P-delta effects arising from gravity loads are included in the pushover curve for the first mode but not for the other modes. The solution of the nonlinear Eq. (12) provides $D_{n}(t)$, which is substituted into Eq. (2) to obtain roof displacement due to $\mathbf{p}_{\mathrm{eff}, n}(t)$; and Eq. (5) provides the response due to the total excitation $\mathbf{p}_{\text {eff }}(t)$.

\section{Underlying Assumptions and Accuracy}

The UMRHA procedure is based on two principal assumptions and approximations: (1) the coupling between modal coordinates $q_{n}(t)$ arising from yielding of the system is neglected; and (2) the superposition of responses to $\mathbf{p}_{\mathrm{eff}, n}(t)(n=1,2 \ldots N)$ according to Eq. (5), while strictly valid only for linearly elastic systems, is only an approximation for inelastic systems.

While the coupled nonlinear equation must be solved to determine the "exact" roof displacement due to $\mathbf{p}_{\text {eff, }, n}(t)$, the first assumption implies that an approximate result is given by $u_{r n}(t)$ defined in Eq. (2) with $D_{n}(t)$ determined by nonlinear RHA of the $n$th mode inelastic SDF system, governed by Eq. (12). The accuracy of this approximate result has been confirmed for buildings ranging from 3 to 18 stories, SDF system ductility factor varying from 1 to 6, and 20 ground motions (Chopra et al. 2001) and for a SAC building (Chopra and Goel 2002).

The second assumption implies that superposition of the "exact" roof displacements $u_{r n}(t)$ due to $\mathbf{p}_{\text {eff, } n}(t)-n$ $=1,2,3 \ldots$ - determined by nonlinear RHA of the MDF systemwill provide a good approximation to the "exact" response of the MDF system to $\mathbf{p}_{\text {eff }}(t)$. Based on the valid first assumption, therefore, the superposition of the approximate $u_{r n}(t)$ determined using $D_{n}(t)$ of the $n$th "mode" inelastic SDF system should provide a good approximation to the "exact" value, however, as demonstrated later, this is not always the case.

\section{Modal Pushover Analysis}

The peak value $u_{r n o}$ of $u_{r n}(t)$, the roof displacement of the inelastic MDF system due to earthquake forces $\mathbf{p}_{\text {eff }, n}(t)$, can be estimated from Eq. (6), where $D_{n}$ is now the peak value of deformation $D_{n}(t)$ of the $n$th "mode" inelastic SDF system. It can be determined by solving Eq. (12) or from the inelastic response (or design spectrum) (Chopra 2001; Secs. 7.6 and 7.12). We will refer to $u_{r n o}$ as the peak "modal" response even in the case of inelastic systems.

The peak modal responses $u_{r n o}$, each determined by pushover analysis for force distribution $\mathbf{s}_{n}^{*}$ and dynamic analysis of the $n$th "mode" inelastic SDF system, may be combined using an appropriate modal combination rule [e.g., Eq. (7)] -although it is strictly valid only for elastic response - to obtain a MPA estimate of the total roof displacement

$$
\left(u_{r}\right)_{\mathrm{MPA}}=\left(\sum_{n=1}^{N} u_{r n o}^{2}\right)^{1 / 2}
$$

The MPA procedure when applied to linear systems is equivalent to the standard RSA procedure (Chopra and Goel 2002).

\section{Single-Degree-of-Freedom System Estimate}

In current nonlinear static (or pushover) analysis procedures, only the first term is retained in Eq. (14) and it is obtained for a SDF system determined from static analysis of the structure subjected to lateral-force distributions specified in FEMA-273 guidelines instead of the distribution defined by Eq. (13). Considering only the first "mode" contribution leads to a SDF system estimate of the roof displacement, which is given by Eq. (8), where $D_{1}$ is now the peak deformation of the first "mode" inelastic SDF system.

\section{Comparative Evaluation of Analysis Procedures: Inelastic Buildings}

\section{Generic Frames}

The median and dispersion of the ratio $\left(u_{r}^{*}\right)_{\mathrm{SDF}}$ are plotted versus the fundamental vibration period (or number of stories) in Figs. 5(a and b) and versus the design ductility factor $\mu$ in Figs. 6(a and b). This median ratio starts very close to 1.0 for 3 -story frames, irrespective of the design ductility factor $\mu$, but increasingly differs from 1.0 and becomes increasingly dependent on $\mu$ as $T_{1}$ becomes longer [see Figs. 5(a) and 6(a)]. The SDF system estimate $\left(u_{r}\right)_{\mathrm{SDF}}$ is biased as expected, but the nature and magnitude of this bias depends on $\mu$. For smaller $\mu$, the SDF system method underestimates the roof displacement; this bias increases for longer-period systems (or taller frames) just as in the case of elastic systems (Fig. 1). The situation is reversed for larger $\mu$; for $\mu=6$ the SDF system method overestimates the roof displacement, and this bias increases for taller frames [Figs. 5(a) and $6(\mathrm{a})]$. For intermediate values of $\mu$, the ratio $\left(u_{r}^{*}\right)_{\mathrm{SDF}}$ is closer to one, implying that the SDF system estimate of roof displacement is relatively more accurate for frames of all heights. The dispersion tends to increase for taller frames for every value of $\mu$ [Fig. $5(b)$. It is smallest for elastic systems and tends to increase with the design ductility factor, but this trend is not perfect [see Fig. 6(b)].

Including higher "mode" contributions according to the MPA procedure obviously increases the estimate $\left(u_{r}\right)_{\mathrm{MPA}}$ of the roof 


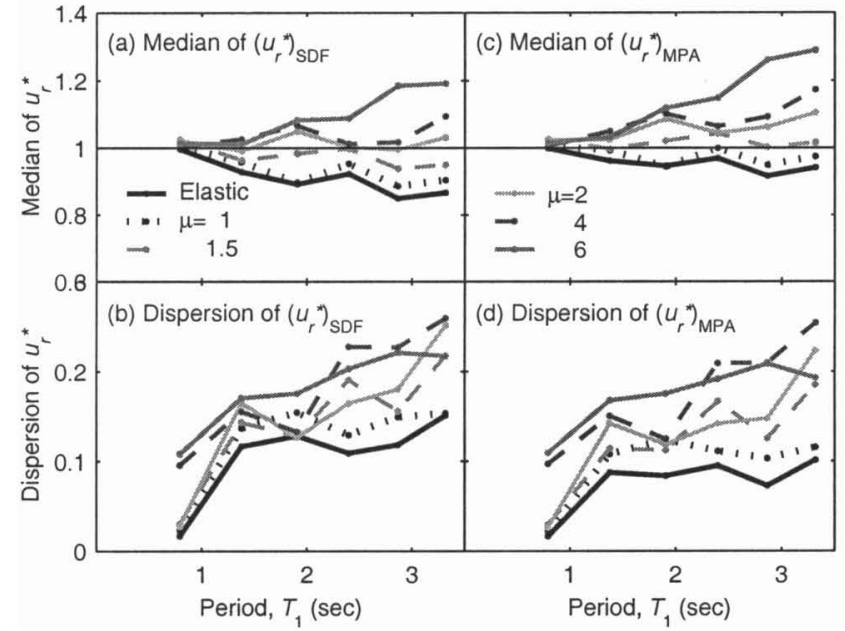

Fig. 5. Median and dispersion of $\left(u_{r}^{*}\right)_{\mathrm{SDF}}$ and $\left(u_{r}^{*}\right)_{\mathrm{MPA}}$ versus fundamental vibration period $T_{1}$ for generic inelastic frames

displacement relative to the SDF system estimate $\left(u_{r}\right)_{\mathrm{SDF}}$, thus the $\left(u_{r}^{*}\right)_{\text {MPA }}$ plot is shifted up [compare Figs. 5(a and c)]. As a result, MPA overestimates the roof displacement except for elastic or nearly elastic cases where it underestimates to a lesser degree than the SDF estimate. Generally, this overestimation is modest, except for combinations of very long periods and large design ductility values. Including higher-"mode" contributions to the roof displacement reduces the dispersion significantly for lower values of $\mu$ and, to a lesser degree, for larger values of $\mu$.

Fig. 7 shows the histograms of the 20 values of the ratio $\left(u_{r}^{*}\right)_{\mathrm{SDF}}$ together with the range of values and median value of this ratio for each of the six frames with design ductility factor $\mu=6$. The SDF system estimate of roof displacement can be alarmingly small for individual ground motions for frames as low as 6 stories and, of course, for taller frames. The smallest values of $\left(u_{r}^{*}\right)_{\text {SDF }}$ observed are $0.89,0.72,0.73,0.66,0.72$, and 0.75 for 3-, 6-, 9-, 12-, 15-, and 18-story frames, respectively. The SDF system estimate can also be surprisingly large for a few excitations, especially for taller frames. The largest values of $\left(u_{r}^{*}\right)_{\mathrm{SDF}}$ are $1.40,1.62,1.46,1.38,1.58$, and 1.88 for 3-, 6-, 9-, 12-, 15-,

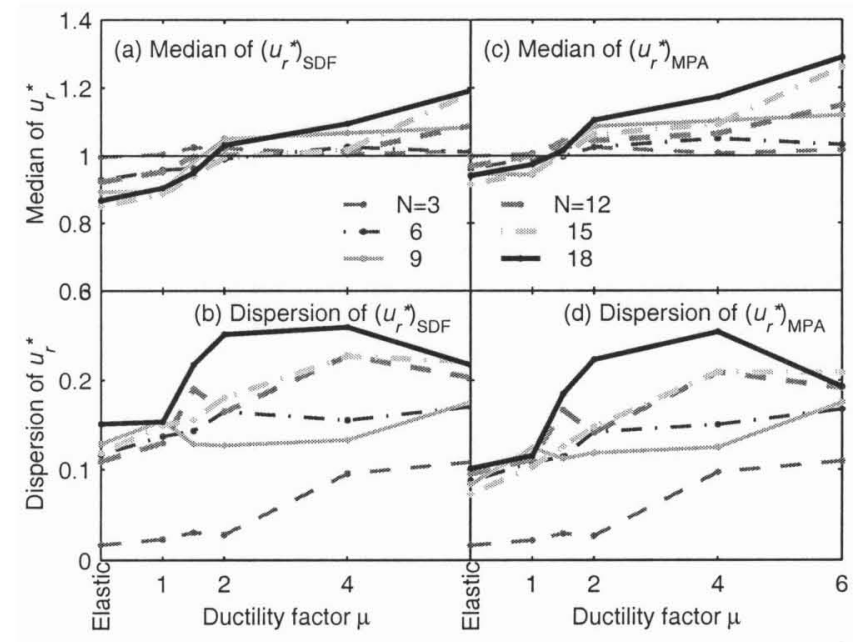

Fig. 6. Median and dispersion of $\left(u_{r}^{*}\right)_{\mathrm{SDF}}$ and $\left(u_{r}^{*}\right)_{\mathrm{MPA}}$ versus $\mu$ for generic inelastic frames of $3,6,9,12,15$, and 18 stories

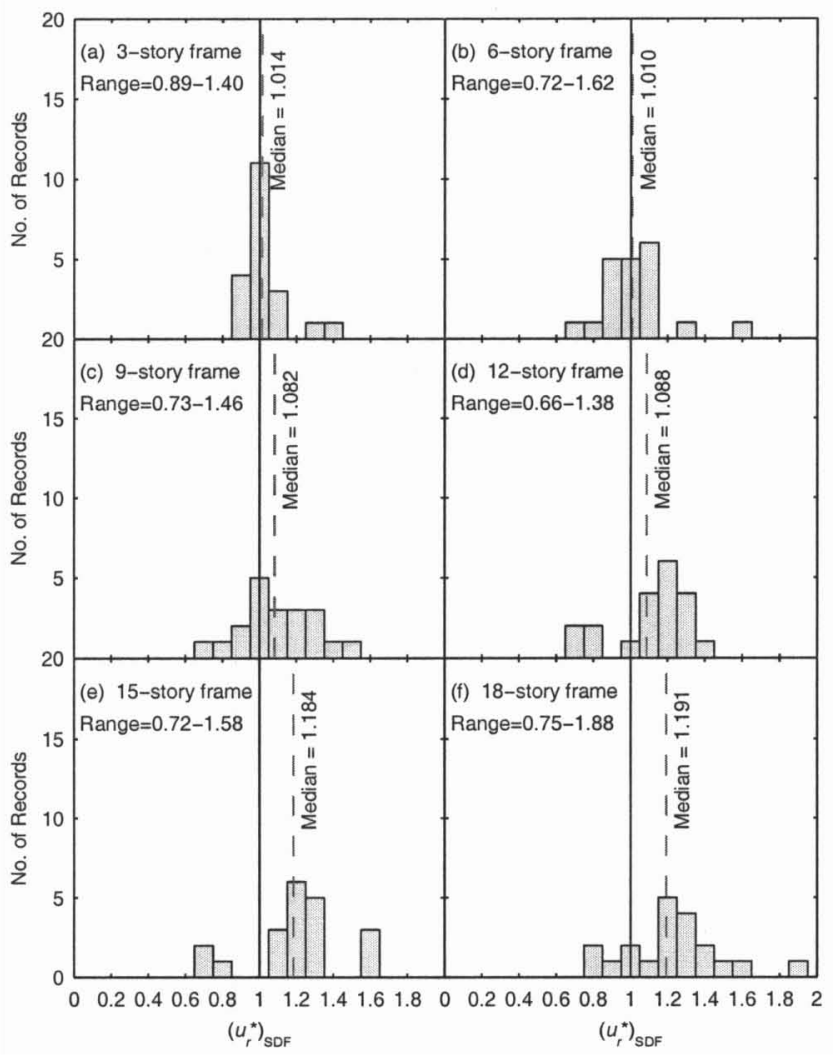

Fig. 7. Histograms of ratio $\left(u_{r}^{*}\right)_{\mathrm{SDF}}$ for generic frames with design ductility factor $\mu=6$; range of values and median value of this ratio are noted

and 18-story frames, respectively. A comparison of Figs. 7 and 2 indicates that the $\left(u_{r}^{*}\right)_{\mathrm{SDF}}$ ratio varies over a much wider range for inelastic systems-and good accuracy occurs less oftencompared to elastic systems. This large error in the SDF system estimate of roof displacement is investigated further in Chopra et al. (2001).

\section{SAC Buildings}

To facilitate interpretation of subsequent results, Fig. 8 shows the first "mode" pushover curves for the six SAC buildings for two cases: P-delta effects due to gravity loads excluded or included, with the peak displacement identified for each of the 20 ground motions except for those excitations that caused collapse of the system. In the presence of P-delta effects, the number of excitations that caused collapse of the first- "mode" SDF systems is one for the Seattle 9-story building, three for the Los Angeles 9-story building, and six for the Los Angeles 20-story building. For these buildings, the statistics of displacement ratios $\left(u_{r}^{*}\right)_{\mathrm{SDF}}$ and $\left(u_{r}^{*}\right)_{\text {MPA }}$ were calculated by the counting method described earlier. Note that nonlinear RHA of these buildings and ground motions predicted a finite value of displacement and did not predict their collapse except for the Los Angeles 20-story building due to one ground motion.

Table 2 shows the median and dispersion of the ratio $\left(u_{r}^{*}\right)_{\mathrm{SDF}}$ for six SAC buildings for two cases: P-delta effects excluded or included. When these effects are excluded, the SDF system estimate of roof displacement has small bias for Seattle buildings, overestimates by 6 and $11 \%$ for Los Angeles 9- and 20-story buildings, and underestimates by 17 and $22 \%$ for Boston 9- and 

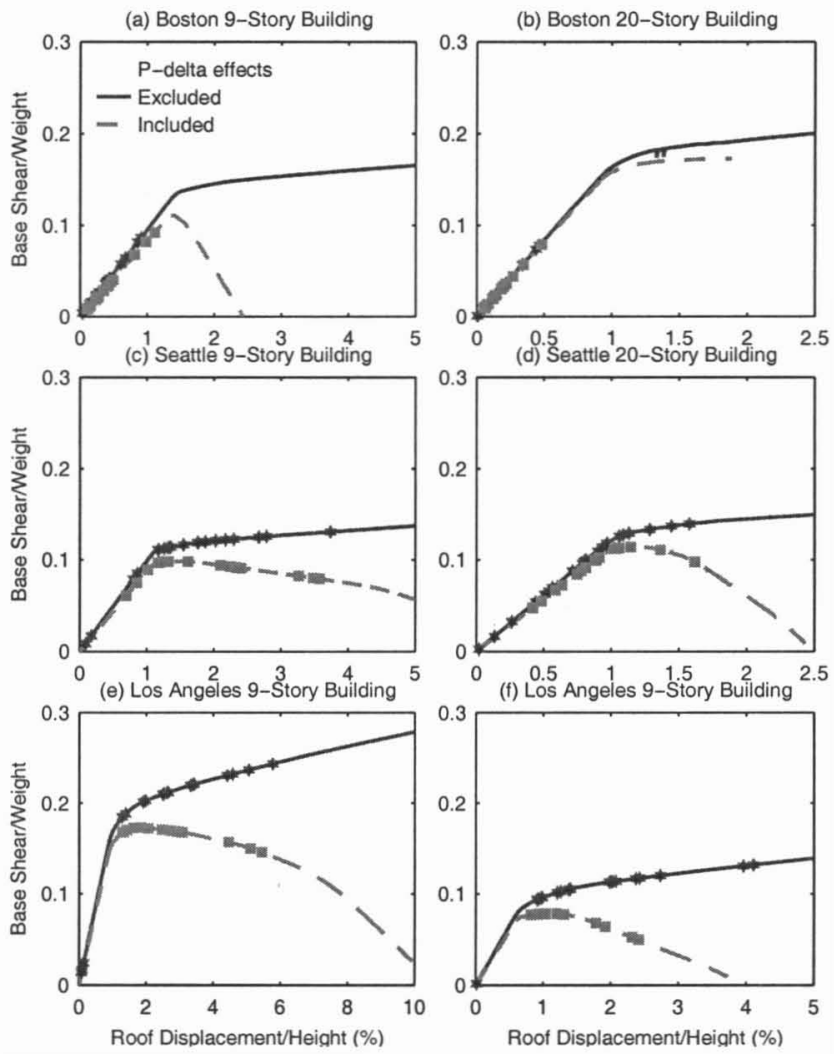

Fig. 8. First "mode" pushover curves for SAC buildings for two cases: P-delta effects due to gravity loads excluded or included

20 -story buildings, respectively. The dispersion is similar for all cases, except that it is much smaller for the Los Angeles 20-story building, which is surprising because this building is driven well into the inelastic range [see Fig. 8(f)].

As shown in Table 2, when gravity-load and P-delta effects are included in both analyses - nonlinear RHA and first-"mode" SDF system - the bias in the SDF system estimate of roof displacement is essentially unaffected for Boston buildings because they respond within their elastic range [see Figs. 8( $a$ and b)] and for the Seattle 20-story building because only a few of the 20 ground motions excited it slightly beyond yield displacement [Fig. 8(d)].
However, P-delta effects influence the response of the other three buildings significantly because most of the 20 ground motions excite them well beyond the yield displacement into the region of negative stiffness [see Figs. 8(c), (e), and (f)] and collapse occurs in some cases. This influence is apparent by the increased bias and dispersion of the SDF system estimate of displacement (see Table 2).

Including higher mode contributions according to the MPA procedure obviously gives a larger roof displacement than the SDF system estimate, thus the median $\left(u_{r}^{*}\right)_{\text {MPA }}$ values shown in Table 3 are larger compared to $\left(u_{r}^{*}\right)_{\mathrm{SDF}}$ values in Table 2 . The roof displacement, excluding P-delta effects, is now quite accurate; it is underestimated by only $5 \%$ for Boston buildings, overestimated by 5 or $7 \%$ for Seattle buildings, and 8 or $17 \%$ for Los Angeles buildings. Not only is the median value estimated more accurately by MPA, the dispersion is reduced for most cases.

As shown in Table 3 with P-delta effects included in nonlinear RHA and MPA, the MPA procedure estimates the median displacement almost perfectly for the Boston 9-story building, within $5 \%$ for the Seattle buildings, and overestimates it 21 or $27 \%$ for the Los Angeles buildings. Only for the Boston 20-story building does the procedure underestimate the displacement significantly-by $12 \%$. P-delta effects increase the dispersion of the MPA estimate for roof displacement for all buildings, with significant increases in four cases. [The dispersion of the Los Angeles 20-story building could not be calculated because the 17 th value (or the 84 th percentile value) required was not available; in this case, more than three excitations caused collapse of the SDF system.]

Figs. 9 and 10 show the histograms of the 20 values of the displacement ratio $\left(u_{r}^{*}\right)_{\mathrm{SDF}}$ together with the range of values and the median values of this ratio for each of the six SAC buildings for two cases: P-delta effects excluded or included. For Los Angeles buildings, which are driven well into the inelastic range, this ratio is larger than one for many excitations, a result consistent with generic frames designed for a large ductility factor $\mu$. For Boston buildings, which remain close to elastic, $\left(u_{r}^{*}\right)_{\mathrm{SDF}}$ is smaller than one for most ground motions, similar to the observation based on earlier elastic analyses (Fig. 4).

If we compare Figs. 10 and 9, note that the range of values for $\left(u_{r}^{*}\right)_{\mathrm{SDF}}$ becomes much wider when P-delta effects due to gravity loads are included, implying that the SDF system estimate of the

Table 2. Median and Dispersion of $\left(u_{r}^{*}\right)_{\mathrm{SDF}}$ for SAC Buildings

Gravity Loads Excluded

Building

Boston 9 story

Boston 20 story

Seattle 9 story

Seattle 20 story

Los Angeles 9 story

Los Angeles 20 story
Median

0.830

0.782

1.01

0.949

1.06

1.11
Dispersion

\subsection{2}

0.192

0.194

0.188

0.194

0.109
Gravity Loads Included

$\begin{array}{cc}\text { Median } & \text { Dispersion } \\ 0.860 & 0.177 \\ 0.721 & 0.244 \\ 0.944^{\mathrm{a}} & 0.411^{\mathrm{a}} \\ 0.947 & 0.208 \\ 1.19^{\mathrm{b}} & 0.331^{\mathrm{b}} \\ 1.19^{\mathrm{c}} & \mathrm{N} / \mathrm{A}^{\mathrm{c}, \mathrm{d}}\end{array}$

${ }^{\text {a } D a t a}$ for excitations that caused collapse of the SDF system are excluded, reducing the number of data to 19; the median and dispersion values are computed by the counting method.

${ }^{b}$ Data for excitations that caused collapse of the SDF system are excluded, reducing the number of data to 17; the median and dispersion values are computed by the counting method.

${ }^{c}$ Data for excitations that caused collapse of the SDF system are excluded, reducing the number of data to 14; the median and dispersion values are computed by the counting method.

${ }^{\mathrm{d}}$ Dispersion could not be calculated because the 17 th value (or the 84 th percentile value) required was not available; in this case, more than three excitations caused collapse of the SDF system. 
Table 3. Median and Dispersion of $\left(u_{r}^{*}\right)_{\mathrm{MPA}}$ for SAC Buildings

Gravity Loads Excluded

Building

Boston 9 story

Boston 20 story

Seattle 9 story

Seattle 20 story

Los Angeles 9 story

Los Angeles 20 story

$\begin{array}{cc}\text { Median } & \text { Dispersion } \\ 0.951 & 0.148 \\ 0.954 & 0.141 \\ 1.07 & 0.191 \\ 1.05 & 0.210 \\ 1.08 & 0.184 \\ 1.17 & 0.100\end{array}$

Gravity Loads Included

$\begin{array}{cc}\text { Median } & \text { Dispersion } \\ 0.995 & 0.159 \\ 0.881 & 0.224 \\ 0.990^{\mathrm{a}} & 0.379^{\mathrm{a}} \\ 1.05 & 0.212 \\ 1.21^{\mathrm{b}} & 0.343^{\mathrm{b}} \\ 1.27^{\mathrm{c}} & \mathrm{N}^{\mathrm{c}} \mathrm{A}\end{array}$

${ }^{\text {a }}$ Data for excitations that caused collapse of the SDF system are excluded, reducing the number of data to 19; the median and dispersion values are computed by the counting method.

${ }^{\mathrm{b}}$ Data for excitations that caused collapse of the SDF system are excluded, reducing the number of data to 17 ; the median and dispersion values are computed by the counting method.

${ }^{c}$ Data for excitations that caused collapse of the SDF system are excluded, reducing the number of data to 14; the median and dispersion values are computed by the counting method.

${ }^{\mathrm{d}}$ Dispersion could not be calculated because the 17 th value (or the 84 th percentile value) required was not available; in this case, more than three excitations caused collapse of the SDF system.

roof displacement may now be considerably less accurate for individual ground motions. Clearly, the SDF system estimate can be alarmingly small (as low as $0.312-0.817$ for the six buildings) or surprisingly large (as large as 1.45-2.15 for Seattle and Los Angeles buildings) for individual ground motions, especially when P-delta effects are included. This situation is worse than indicated by Fig. 10 because it does not include several cases mentioned earlier where the first "mode" SDF system collapsed, whereas the building as a whole did not. The SDF system overestimates the roof displacement of 9-story buildings due to 7 and 12 ground

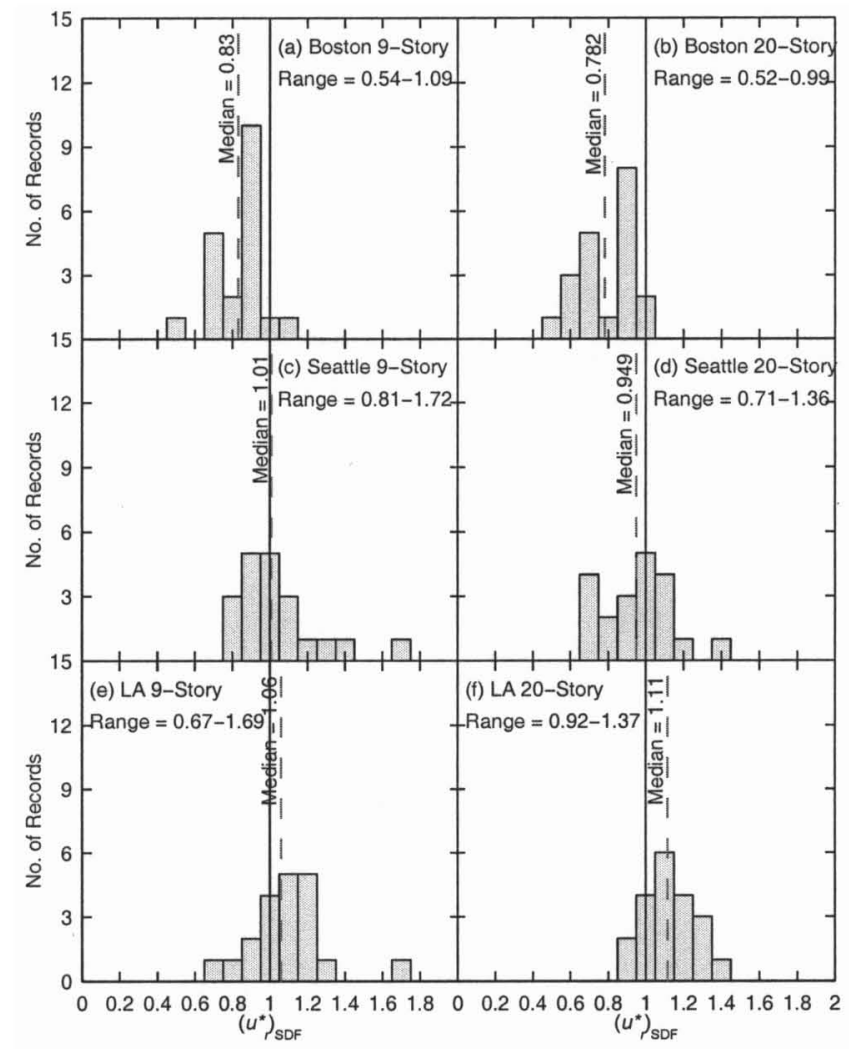

Fig. 9. Histograms of ratio $\left(u_{r}^{*}\right)_{\mathrm{SDF}}$ for SAC buildings excluding P-delta effects due to gravity loads; range of values and median value of this ratio are noted motions for Seattle and Los Angeles locations, respectively; and of 20-story buildings due to 8 excitations for the Seattle structure and 11 for the Los Angeles structure. The histograms of the ratio $\left(u_{r}^{*}\right)_{\mathrm{MPA}}$ shown in Fig. 11 demonstrate that the range of values does not narrow, implying that the error in estimating roof displacement due to individual ground motions can be considerably large even when higher "mode" contributions are included.

To investigate the large discrepancy in the SDF system estimate of roof displacement, the response history of "modal" contributions, the combined response determined by UMRHA, and

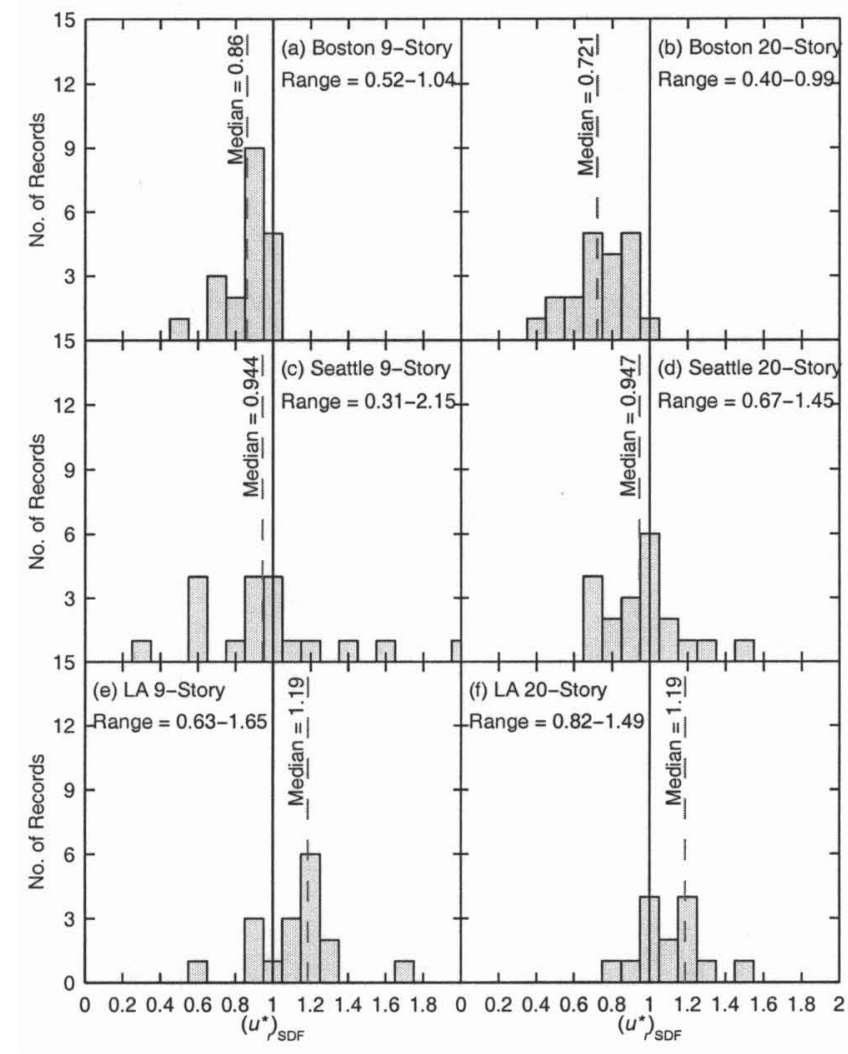

Fig. 10. Histograms of ratio $\left(u_{r}^{*}\right)_{\mathrm{SDF}}$ for SAC buildings including P-delta effects due to gravity loads; range of values and median value of this ratio are noted 


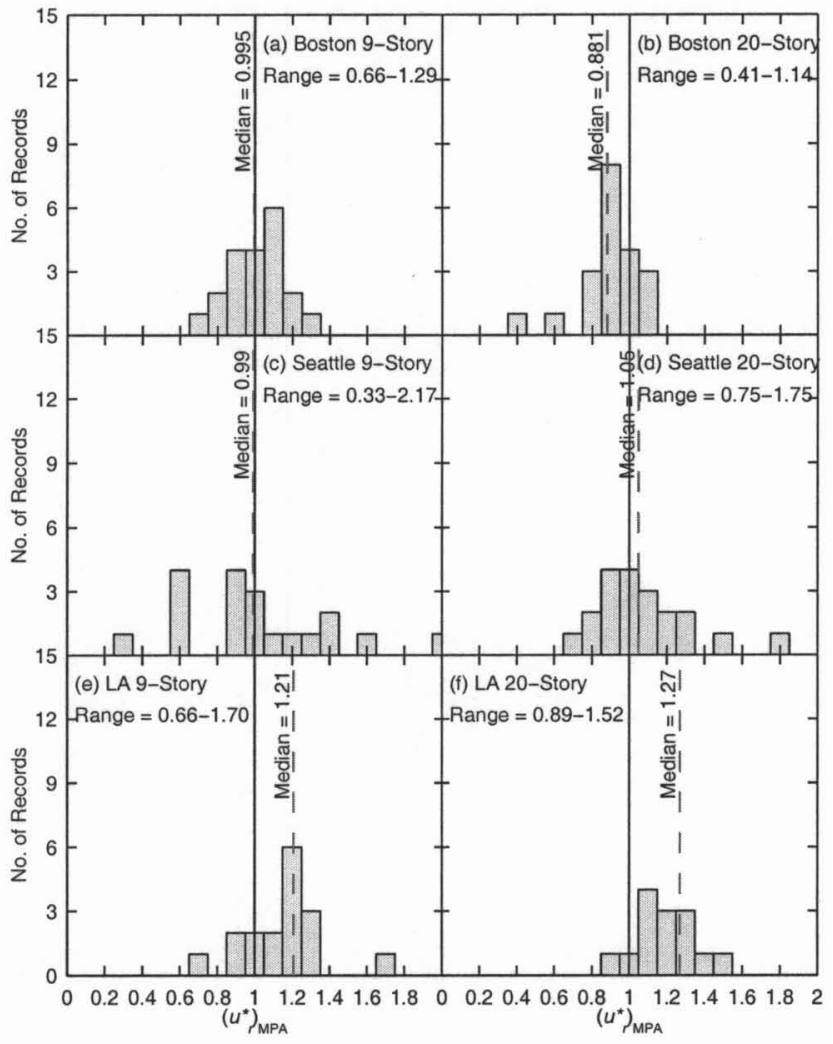

Fig. 11. Histograms of ratio $\left(u_{r}^{*}\right)_{\mathrm{MPA}}$ for SAC buildings including P-delta effects due to gravity loads; range of values and median value of this ratio are noted

the "exact" response from nonlinear RHA are presented for the Los Angeles 9-story building due to three of the 20 ground motions in Figs. 12(a, b, and c), respectively; also included is the $\left(u_{r}\right)_{\mathrm{MPA}}$ value determined from Eq. (14). In the first case the first "mode" contribution is dominant; the peak response occurs at the end of the first large inelastic excursion before the yielding induced drift away from the zero-displacement position takes place, and the SDF system estimate is highly accurate [see Fig. 12(a)]. In the second case the first "mode" contribution is dominant, but its permanent drift is much smaller than in the "exact" response determined by nonlinear RHA [see Fig. 12(b)], and the SDF system method underestimates the roof displacement by $37 \%$. In the third case the first "mode" contribution is dominant but its permanent drift away from the initial position is much larger than in the "exact" response by nonlinear RHA [see Fig. 12(c)]. Consequently, the SDF system method overestimates the roof displacement by $65 \%$.

For the latter two ground motions, little if any improvement is achieved by including higher "mode" contributions according to the UMRHA procedure. This persistent discrepancy implies that the second assumption identified earlier in developing the UMRHA procedure is not always valid; it works in Fig. 12(a) but not in Figs. 12(b or c). When it does not work, the roof displacement $\left(u_{r}\right)_{\text {MPA }}$ estimated by MPA is also inaccurate (see values noted in Fig. 12). In principle, this estimate should be less accurate than the UMRHA results because it contains additional modal combination errors, however, that is not always the case because

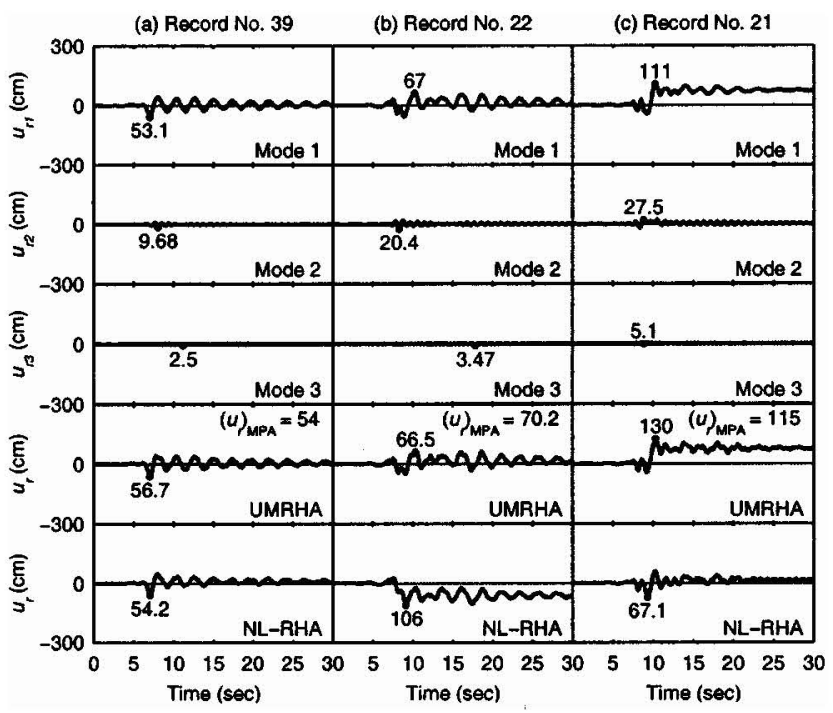

Fig. 12. Response histories of roof displacement of Los Angeles nine-story building including P-delta effects due to gravity loads for three ground motions: individual "modal" responses, combined response from uncoupled modal response history analysis, and "exact" response from nonlinear response history analysis; modal pushover analysis estimate of roof displacement is also noted

errors due to various approximations can cancel or reinforce each other.

\section{Implications for Federal Emergency Management Agency Pushover Analyses}

The SDF system was derived herein from the pushover curve using the lateral force distribution associated with the fundamental vibration mode of the corresponding linear system [Eq. (13)]. However, the force distributions defined in FEMA-273 are different:

1. "Uniform" distribution: $s_{j}^{*}=m_{j}$ (where the floor number $j$ $=1,2 \ldots N)$;

2. Equivalent lateral force distribution: $s_{j}^{*}=m_{j} h_{j}^{k}$ where $h_{j}$ is the height of the $j$ th floor above the base, and the exponent $k=1$ for fundamental period $T_{1} \leqslant 0.5 \mathrm{~s}, k=2$ for $T_{1} \geqslant 2.5 \mathrm{~s}$; and varies linearly in between; and

3. SRSS distribution: $\mathbf{s}^{*}$ is defined by the lateral forces back calculated from the story shears determined by response spectrum analysis of the structure, assumed to be linearly elastic.

Are the results presented earlier in this paper relevant to the FEMA-273 force distributions? To answer this question, Fig. 13(a) compares the pushover curves for the Los Angeles 9-story building associated with these force distributions together with the first "mode" result; Fig. 13(b) shows the peak deformations of the SDF systems associated with three FEMA force distributions plotted against the value from the first "mode" inelastic SDF system. All these pushover curves and the deformations of the various SDF systems are similar. Thus the general observations concerning the SDF system estimate of roof displacement presented earlier are valid for the FEMA-273 force distributions. 

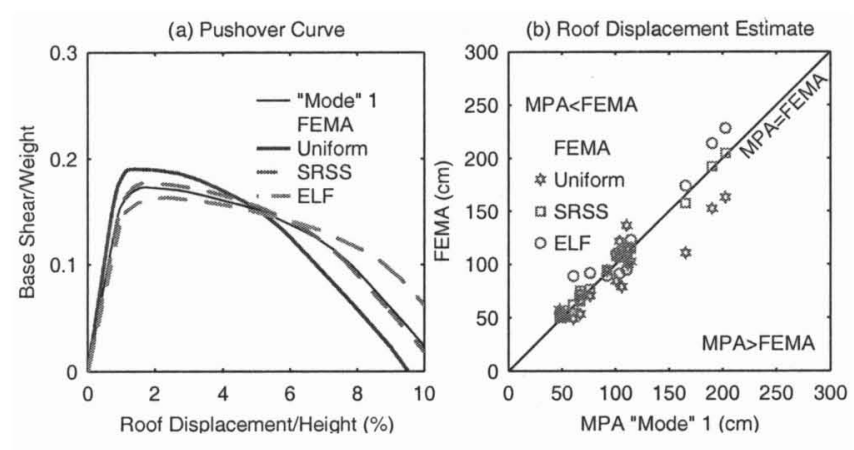

Fig. 13. (a) Pushover curves for Los Angeles nine-story building associated with three Federal Emergency Management Agency-273 force distributions and first "mode" distribution; and (b) peak roof displacement from three Federal Emergency Management Agency sulfate deterioration factor systems plotted against its value from first-"mode" inelastic sulfate deterioration factor system; P-delta effects due to gravity loads are included for all cases

\section{Conclusions}

\section{Elastic Buildings}

1. When compared to "exact" values obtained from rigorous nonlinear RHA, the first-mode SDF system underestimates the median value of roof displacement over an ensemble of ground motions. The bias and dispersion of the displacement ratio $\left(u_{r}^{*}\right)_{\mathrm{SDF}}$ increase for longer-period frames, median values as low as 0.850 for generic frames, and 0.741 for SAC buildings were observed, implying that the SDF system underestimates roof displacement by 15 and $26 \%$, respectively. The SDF system estimate of roof displacement due to individual excitations can be alarmingly inaccurate.

2. When higher mode contributions to response are included in RSA, the bias and dispersion of the displacement ratio $\left(u_{r}^{*}\right)_{\mathrm{RSA}}$ reduce; the remaining bias and dispersion are due to approximations associated with modal combination rules.

\section{Inelastic Buildings}

1. The first "mode" SDF system estimate of the median roof displacement is biased, as expected, but the nature and magnitude of this bias depends on how far the structure is driven into the inelastic range, characterized by an overall ductility demand $\mu$. For larger $\mu$, the SDF system method overestimates the median roof displacement, and this bias increases for longer-period systems. The situation is reversed for small $\mu$; the SDF system method underestimates roof displacement, and this bias increases for longer-period systems.

2. The median values of $\left(u_{r}^{*}\right)_{\mathrm{SDF}}$ ranged from 0.85 for 1.19 for generic frames, from 0.78 to 1.11 for SAC buildings without P-delta effects due to gravity loads, implying an underestimation by $22 \%$ to an overestimation by $11 \%$, respectively.

3. The dispersion of the displacement ratio $\left(u_{r}^{*}\right)_{\mathrm{SDF}}$ tends to increase for longer-period systems for every value of $\mu$.

4. The bias and dispersion in the SDF estimate of roof displacement increase when P-delta effects (due to gravity loads) are included.

5. The SDF estimate of roof displacement due to individual ground motions can be alarmingly small (as low as $0.312-$ 0.817 of the "exact" value for the six SAC buildings) or surprisingly large (as large as 1.45-2.15 of the "exact" value for Seattle and Los Angeles buildings), especially when P-delta effects are included. The situation is worse than indicated by these data because they do not include several cases where the first "mode" SDF system collapsed, whereas the building as a whole did not.

6. This large discrepancy arises because for individual grounds motion the SDF system may underestimate or overestimate the yielding-induced permanent drift in the "exact" response determined by nonlinear RHA.

7. While this discrepancy is not improved significantly by including higher "mode" contributions, the MPA procedure has the advantage of reducing the dispersion in the roof displacement and the underestimation of the median roof displacement for elastic or nearly elastic cases at the expense of increasing slightly the overestimate of roof displacement of buildings responding far into the inelastic range.

\section{Acknowledgments}

This research investigation is funded by the National Science Foundation under Grant No. CMS-9812531, a part of the U.S.Japan Cooperative Research in Urban Earthquake Disaster Mitigation. This financial support is gratefully acknowledged. The writers have benefited from discussion with Chris D. Poland, Jon A. Heintz, and Kent Yu of Degenkolb Engineers, and Helmut Krawinkler, E. Miranda, and C. Allin Cornell of Stanford University.

\section{References}

Applied Technology Council (ATC). (1996). "Seismic evaluation and retrofit of concrete buildings." Rep. No. ATC-40, Redwood City, Calif.

Benjamin, J. R., and Cornell, C. A. (1970). Probability, statistics, and decision for civil engineers, McGraw-Hill, New York.

Building Seismic Safety Council (BSSC). (1997). NEHRP guidelines for the seismic rehabilitation of buildings, FEMA-273 and Commentary FEMA-274, Federal Emergency Management Agency, Washington, D.C.

Chintanapakdee, C., and Chopra, A. K. (2003). "Evaluation of modal pushover analyses for generic frames." Earthquake Eng. Struct. Dyn., 32(3), 417-442.

Chopra, A. K. (2001). Dynamics of structures: theory and applications to earthquake engineering, 2nd Ed., Prentice Hall, Englewood Cliffs, N.J.

Chopra, A. K., and Goel, R. K. (2002). “A modal pushover analysis procedure for estimating seismic demands for buildings." Earthquake Eng. Struct. Dyn., 31(3), 561-582.

Chopra, A. K., Goel, R. K., and Chintanapakdee, C. (2001). "Statistics of SDF-system estimate of roof displacement for pushover analysis of buildings." PEER Rep. No. 2001/16, Pacific Earthquake, Engineering Research Center, Univ. of Calif., Berkeley, Calif.

Collins, K. R., Wen, Y. K., and Foutch, D. A. (1996). "Dual-level seismic design: a reliability-based methodology." Earthquake Eng. Struct. Dyn., 25(12), 1433-1467.

Goel, R. K., and Chopra, A. K. (1997). "Period formulas for momentresisting frame buildings." J. Struct. Eng., 23(11), 1454-1461.

Gupta, A., and Krawinkler, H. (1999). "Seismic demands for performance evaluation of steel moment resisting frame structures (SAC Task 5.4.3)." Rep. No. 132, John A. Blume Earthquake Engineering Center, Stanford Univ., Stanford, Calif.

Gupta, A., and Krawinkler, H. (2000). "Estimation of seismic drift demand for frame structures." Earthquake Eng. Struct. Dyn., 29(9), 1287-1305. 
Miranda, E. (1991). "Evaluation and upgrading of existing buildings." Ph.D. dissertation, Univ. of California, Berkeley, Calif.

Miranda, E. (1997). "Estimation of maximum interstory-drift demands in displacement based design." Seismic design methodologies for the next generation of codes, P. Fajfar and H. Krawinkler, eds., Balkema, Rotterdam, The Netherlands, 253-264.
Miranda, E. (1999). "Approximate seismic lateral deformation demands in multistory buildings." J. Struct. Eng., 125(4), 417-425.

Somerville, P., Smith, N., Punyamurthula, S., and Sun, J. (1997). "Development of ground motion time histories for Phase 2 of the FEMA/ SAC steel project." SAC Background Document Rep. No. SAC/BD-9/ 04, SAC Joint Venture, Sacramento, Calif. 